viên cử nhân trường đại học y tế công cộng năm 2017 - khảo sát bằng bô công cư Dass 21, Luận văn thạc sỹ y tế công cộ̂ng, Trưởing đại học y tế công cộng Hà Nội, Hà Nội

5. Phạm Thị Huyên Trang (2013), Thực trạng stress trong sinh viên trương Đai học Y Hà Nội, Khóa luận tốt nghiệp y khoa, Trường Đại học Y Hà Nội, Hà Nội
6. Vũ Dũng (2015), Thực trạng stress của sinh viên điều dướng Đai hoc Thăng Long năm 2015 và một số yếu tố liên quan, Luận văn thạc sĩ y tế công cộng, Trường đại học Y tế công cộng Hà Nội, Hà Nội.

7. Stuart Keekman and HanNa Lim (2014) "Factors Related to Financial Stress among College students", Journal of Financial Therapy. 5(1).

\title{
ĐĂC ĐIỂM CƠ THẮT THỰC QUẢN TRÊN Ở NHÓM BỆNH NHÂN CÓ TRIÊU CHỨNG TRÀO NGƯỢC HỌNG THANH QUẢN VÀ TRÀO NGƯỢC DẠ DÀY THỰC QUUẢN ĐIỂN HÎ̀NH
}

\section{Đào Việt Hằng1,2,3, Trần Thị Thu Trang,4, Lư Thị Minh Huế}

\section{TÓM TẮT}

Nghiên cứu mô tả hồi cứu đặc điểm của cơ thắt thực quản trên (UES) bằng kĩ thuật đo áp lực và nhu động thực quản độ phân giải cao (HRM) ở nhóm bệnh nhân có các triệu chứng nghi ngờ trào ngược họng thanh quản (LPR) và trào ngược điển hình (GERD) tại Phòng khám Đa khoa Hoàng Long từ tháng 6/2020 đến 9/2020. Kết quả nghiên ghi nhận được tî lệ bệnh nhân nhóm LPR, nhómGERD điển hình và nhóm hỗn hợp lần lượt là $18,0 \%, 44,2 \%$ và $37,8 \%$. Trung vị áp lực khi nghỉ và áp lức căn của UES ở nhóm LPR lần lượt là $38,3 \mathrm{mmHg}$ và $14,3 \mathrm{mmHg}$. Tỉ lệ bệnh nhân có giảm trương lực UES và bất thường áp lực căn UES lân lượt là $35,9 \%$ và $64,1 \%$. Không có sự khác biệt có ý nghĩa thống kê về các giá trị đo UES, tỉ lệ bất thường trương lực và áp lực cặn của UES giửa ba nhóm. Co bóp không hiêuu quả là rối loạn nhu động thực quản thường gặp nhất ở cả ba nhóm bệnh nhân được khảo sát.

Tư khoá: Cơ thắt thực quản trên, trào ngược họng thanh quản, đo áp lực và nhuđộng thực quản độ phân giải cao.

\section{SUMMARY \\ CHARACTERISTICS OF UPPER ESOPHAGEAL SPHINCTER IN PATIENTS WITH LARYNGOPHARYNGEAL REFLUX SYMPTOMS AND TYPICAL \\ GASTROESPHAGEAL REFLUX SYMPTOMS}

A prospective study was conducted to describe the upper esophageal sphincter's characteristics on highresolution manometry (HRM) among patients having symptoms suspected laryngopharyngeal reflux (LPR)

${ }^{1}$ Trung tâm nội soi - Bệnh viện Đại học Y Hà Nội

2Trường Đai hoc Y Hà Nôi

${ }^{3}$ Viện nghiên cứu và đào tạo Tiêu hóa, Gan mật

${ }^{4}$ Trường Đại học Y Dược - Đại học Quốc gia Hà Nội

Chịu trách nhiệm chính: Đào Việt Hằng

Email: hangdao.fsh@gmail.com

Ngày nhận bài: 22.2.2021

Ngày phản biên khoa học: 30.3.2021

Ngày duyệt bài: 12.4.2021 and those having typical symptoms of gastroesophageal reflux disease (GERD). Patients were recruited at Hoang Long Clinic between June 2020 and September 2020. The prevalence of patients in each group (LPR, typical GERD, and those with mixed symptoms) were $18.0 \%, 44.2 \%$, and $37.8 \%$, respectively. The medians of resting and residual UES pressure were $38.3 \mathrm{mmHg}$ and $14.3 \mathrm{mmHg}$, respectively. The prevalence of patients having low resting UES pressure and abnormal residual UES pressure were $35.9 \%$ and $64.1 \%$, respectively. Ineffective esophageal motility was the most common motor dysfunction in the three groups.

Keywords: upper esophageal sphincter (UES), laryngopharyngeal reflux (LPR), high-resolution manometry (HRM).

\section{I. ĐẶT VẤN ĐỀ}

Trào ngược họng-thanh quản (Laryngopharyngeal reflux - LPR) là tình trạng trào ngược dịch dạ dày qua cơ thắt thực quản trên lên tới họng và thanh quản. ${ }^{1}$ Triệu chứng lâm sàng của tình trạng này thường không đặc hiệu với các biểu hiện thường gặp như ho, rát họng kéo dài, khò khè, cảm giác có khối hoặc nghẹn ở cổ. Cơ chế gây nên tình trạng LPR bao gồmnhiều yếu tố như bất thường áp lực vùng cơ thắt thực quản trên (UES) và các rối loạn nhu động kèm theo tại thực quản. ${ }^{1}$ Trong đó, trương lực UES là một trong các yếu tố chính trong cơ chế chống lại dịch trào ngược từ dạ dày lên đến vùng họng-thanh quản. ${ }^{2}$ Một số nghiên cứu trước đây cho thấy nhóm LPR có trương lực UES thấp hơn và bất thường sự giãn UES so với nhóm GERD điển hình và nhóm chứng khỏe mạnh. 3,4 Với đặc điểm giải phẫu phức tạp, chiều dài của vùng UES ngắn và hoạt động co bóp diễn ra nhanh, việc khảo sát đặc điểm về áp lực và hoạt động co bóp của UES còn hạn chế khi sử dụng phương pháp đo áp lực và nhu động truyền thống. Sự ra đời kĩ thuật đo áp lực và nhu động độ phân giải cao (HRM) sử dụng catheter 
có nhiều thụ thể nhận cảm áp lực, khoảng cách giữa các thụ thể ngắn so với phương pháp đo truyền thốngcho phép tiếp cận, đánh giá vai trò của UES chính xác và thuận lợi hơn. Tại Việt Nam, chưa có nhiều dữ liệu công bố tập trung vào đánh giá về chức năng của UES trong các bệnh lý của thực quản và hầu họng. Trên cơ sở đó, nghiên cứu của chúng tôi có mục tiêu khảo sát đặc điểm của UES bằng kĩ thuật đo áp lực và nhu động thực quản độ phân giải cao ở nhóm bệnh nhân có các triệu chứng trào ngược ngoài thực quản.

\section{II. ĐỐI TƯỢNG VÀ PHƯƠ'NG PHÁP NGHIÊN CỨU}

Đối tượng: Tất cả các bệnh nhâncó ít nhất một triệu chứng trào ngược điển hình (GERD) hoặc triệu chứngnghi ngờ trào ngược họng thanh quản (LPR) tiến hành đo áp lực và nhu động thực quản độ phân giải cao (HRM) và nội soi đường tiêu hóa trên, từ tháng 6/2020 đến tháng 9/2020 tại Phòng khám đa khoa Hoàng Long - Viện nghiên cứu và đào tạo Tiêu hóa, Gan mật.

Trong đó:

- Triệu chứng nghi ngờ trào ngược họng thanh quản (LPR) bao gồm: viêm họng mạn tính, ho kéo dài và cảm giác có khối ở cổ (globus sensation)

- Triệu chứng trào ngượcđiển hình (GERD) bao gồm: nóng rát sau xương ức hoặc cảm giác trào ngược

Đo áp lực và nhu động thực quản độ phân giải cao (HRM). Kĩ thuật HRM được tiến hành trên hệ thống Solar GI, với catheter loại bơm nước 22 kênh. Catheter được đặt qua đường mũi, trong tư thế ngồi. Áp lực khi nghỉ của cơ thắt thực quản trên (UES) và cơ thắt thực quản dưới (LES) được đo trong thời gian tối thiểu 30 giây sau đó thực hiện ít nhất 10 nhịp nuốt đơn (mối lần $5 \mathrm{ml}$ nước), và 2 lần nhịp nuốt nhanh liên tục (bơm 5 nhịp liên tiếp, mỗi nhịp $2 \mathrm{ml}$ nước). Mỗi lần thực hiện cách nhau ít nhất 20 giây. Chẩn đoán trên HRM được dựa theo phân loại Chicago version 3.0.

Áp lực khi nghỉ của UES được phân loại thành ba nhóm: thấp $(<34 \mathrm{mmHg})$, bình thường (34$104 \mathrm{mmHg})$ và cao $(>104 \mathrm{mmHg})$. Áp lực cặn (residual pressure) của UES được phân loại thành 2 nhóm: bình thường $(<12 \mathrm{mmHg})$ và cao $(\geq 12 \mathrm{mmHg}){ }^{1}$

Phân tích số liệu. Dữ liệu được nhập và xử lí bằng phần mềm SPSS version 22.0. Các biến định tính được biểu diễn dưới dạng tỉ lệ (phần trăm), các biến định lượng được biểu diễn dưới dạng trung bình \pm độ lệch chuẩn hoặc trung vị (tứ phân vị). Sự khác biệt giữa các nhóm độc lập kiểm định bằng Chi-square test, Independentsample T-test.

\section{KẾT QUẢ NGHIÊN CỨU}

Trong thời gian nghiên cứu, tỉ lệ bệnh nhân có triệu chứng GERD điển hình kết hợp với các triệu chứng nghi ngờ trào ngược họng thanh quản (nhóm GERD +LPR) chiếm tỉ lệ cao nhất $(44,2 \%)$, tỉ lệ bệnh nhân đến khám chỉ do các triệu chứng nghi ngờ trào ngược họng thanh quản (nhóm LPR) chiếm tỉ lệ thấp nhất $(18,0 \%)$.

Bảng 1 trình bày các đặc điểm về tuối, giới, BMI, và kết quả nội soi đường tiêu hóa trên ở 3 nhóm LPR, GERD và nhóm hỗn hợp (GERD + LPR). Ở cả 3 nhóm, tỉ lệ nữ giới đều chiếm tỉ lệ cao hơn nam giới. Tuổi trung bình, giá trị BMI, tỉ lệ bệnh nhân theo phân loại BMI không có sự khác biệt có ý nghĩa thống kể. Về kết quả nội soi, viêm thực quản trào ngược có tỉ lệ thấp nhất ở nhóm LPR (43,5\%), tuy nhiên không có sự khác biệt có ý nghĩa thống kê với nhóm GERD và nhóm hốn hợp. Tỉ lệ Barrett thực quản và thoát vị hoành cũng khổng có sự khác biệt giữa ba nhóm.

Bảng 1: Đặc điểm chung nhóm nghiên cứu

\begin{tabular}{|c|c|c|c|c|}
\hline Đặc điểm & $\begin{array}{c}\text { LPR } \\
(\mathbf{n = 9 2 )}\end{array}$ & $\begin{array}{c}\text { GERD } \\
(\mathbf{n = 1 9 3 )}\end{array}$ & $\begin{array}{c}\text { GERD + LPR } \\
(\mathbf{n}=\mathbf{2 2 6})\end{array}$ & $\mathbf{p}$ \\
\hline Nam & $32(34,8)$ & $77(39,9)$ & $81(35,8)$ & 0,60 \\
Nữ & $60(65,2)$ & $116(60,1)$ & $145(64,2)$ & 0,6 \\
\hline Tuối & $46,0 \pm 13,7$ & $45,5 \pm 12,3$ & $45,6 \pm 12,3$ & 0,83 \\
\hline BMI & $22,1 \pm 2,8$ & $21,8 \pm 2,6$ & $21,7 \pm 2,5$ & 0,55 \\
\hline BMI phân loại & & & & 0,65 \\
\hline Thiếu cân $\left(<18,5 \mathrm{~kg} / \mathrm{m}^{2}\right)$ & $7(7,6)$ & $21(10,9)$ & $23(10,2)$ & \\
\hline Bình thường $\left(18,5-22,9 \mathrm{~kg} / \mathrm{m}^{2}\right)$ & $50(54,3)$ & $108(56,0)$ & $136(60,2)$ & \\
\hline Thữa cân $\left(>23 \mathrm{~kg} / \mathrm{m}^{2}\right)$ & $34(37,0)$ & $63(32,6)$ & $66(29,2)$ & \\
\hline Kết quả nội soi & & & & 0,15 \\
\hline Viêm thực quản trào ngược & 43,5 & 56,4 & 54,4 & \\
\hline LA độ A & $37(40,2)$ & $101(52,3)$ & $118(52,2)$ & \\
\hline LA độ B & $3(3,3)$ & $8(4,1)$ & $5(2,2)$ & \\
\hline
\end{tabular}


VIETNAM MEDICAL JOURNAL N²2 - APRIL - 2021

\begin{tabular}{|c|c|c|c|c|}
\hline LA độ C & 0 & $2(1,0)$ & 0 & \\
\hline LA độ̣ D & 0 & 0 & 0 & \\
\hline Barrett thực quản & $8(8,7)$ & $10(5,2)$ & $15(6,6)$ & 0,63 \\
\hline Thoát vị hoành & $1(1,1)$ & $2(1,0)$ & $4(1,8)$ & 0,79 \\
\hline
\end{tabular}

BMI: chỉ số khối cơ thể, LA: phân độ viêm thực quản trào ngược Los Angeles. Các giá trị định lượng biểu diễn dưới dạng trung bình \pm độ lệch chuẩn, các giá trị định tính biểu diễn dưới dạn $\mathrm{n}(\%)$.

Rối loạn trương lực cơ thắt UES ở nhóm LPR, GERD và nhóm hốn hợp (GERD + LPR) chủ yếu là giảm áp lực chiếm tỉ lệ lần lượt là 35,9\%,37,8\% và 35,8\%. Đối với nhóm LPR, bất thường (tăng hoặc giảm) áp lực khi nghỉ của UES gặp ở 42,4\%, tỉ lệ tăng áp lực cặn UES ở nhóm LPR là 64,1\%. Các giá trị đo của cơ thắt thực quản trên (UES) và cở thắt thực quản dưới (LES) đều không có sự khác biệt có ý nghĩa thống kề giữa ba nhóm. Về nhu động thực quản trên đo HRM, bất thường phổ biến nhất của cả ba nhóm là nhu động thực quản không hiệu quả (IEM) (Bảng 2).

Bảng 2: Đặc điểm trên đo HRM của nhóm nghiên cứu

\begin{tabular}{|c|c|c|c|c|}
\hline Đặc điểm & $\begin{array}{c}\text { LPR } \\
(n=92)\end{array}$ & $\begin{array}{c}\text { GERD } \\
(n=193)\end{array}$ & $\begin{array}{c}\text { GERD + LPR } \\
(n=226)\end{array}$ & p \\
\hline \multicolumn{5}{|c|}{ Cơ thắt thực quản trên (UES) } \\
\hline Chiều dài UES & $5,2(4,6-5,6)$ & $5,1(4,7-5,5)$ & $5,1(4,7-5,6)$ & 0,93 \\
\hline Áp lưc UES khi nghỉ & $38,3(26,9-59,6)$ & $39,7(29,7-54,9)$ & $41,8(29,7-58,5)$ & 0,84 \\
\hline Phân nhóm áp lực UES khi nghỉ & & & & 0,62 \\
\hline Bình thường & $53(57,6)$ & $115(59,6)$ & $136(60,2)$ & \\
\hline Giảm & $33(35,9)$ & $73(37,8)$ & $81(35,8)$ & \\
\hline Tăng & $6(6,5)$ & $5(2,6)$ & $9(4,0)$ & \\
\hline Áp lức căn UES & $14,3(8,9-19,0)$ & $13,9(8,4-18,0)$ & $14,3(8,9-19,0)$ & 0,88 \\
\hline Phân nhóm áp lực cănn UES & & & & 0,86 \\
\hline Bình thường & $33(35,9)$ & $73(38.8)$ & $88(39.1)$ & \\
\hline Tăng & $59(64,1)$ & $115(61.2)$ & $137(60.9)$ & \\
\hline \multicolumn{5}{|c|}{ Cơ thăt thực quản dưới (LES) } \\
\hline Áp lực LES khi nghỉ & $15,6(11,2-24,5)$ & $17,3(13,3-23,9)$ & $16,2(12,9-23,2)$ & 0.50 \\
\hline IRP4s & $4,5(2,7-7,1)$ & $5,4(3,4-8,0)$ & $5,6(3,5-8,0)$ & 0.13 \\
\hline \multicolumn{5}{|c|}{ Chấn đoán Chicago 3.0} \\
\hline Bình thường & $38(54,3)$ & $104(53,9)$ & $96(42,5)$ & \\
\hline Nhu động không hiệu quả & $50(54,3)$ & $78(40,4)$ & $112(49,6)$ & \\
\hline Thực quản ngắt quãng & 0 & $1(0,5)$ & 0 & \\
\hline Mất nhu & 0 & 0 & 0 & \\
\hline Co thắt tâm vị & $2(2,2)$ & $3(1,6)$ & $1(0,4)$ & \\
\hline Tắc nghẽn đường ra & 0 & $2(1,0)$ & $4(1,8)$ & \\
\hline Co bóp đoạn xa & $2(2,2)$ & 0 & $3(1,3)$ & \\
\hline
\end{tabular}

UES: cơ thắt thực quản trên, LES: cơ thắt thực quản dưới, IRP4s: áp lực tích hợp khi nghỉ trong 4 giây. Các giá trị định lượng biểu diễn dưới dạng trung vị (tứ phân vị thứ nhất-tứ phân vị thứ ba), các giá trị định tính biểu diễn dưới dạng $\mathrm{n}(\%)$.

\section{BÀN LUẬN}

Nghiên cứu của chúng tôi khảo sát đặc điểm của cơ thắt thực quản trên trên đo HRM ở nhóm bệnh nhân có các triệu chứng nghi ngờ trào ngược họng thanh quản (LPR) so với nhóm chỉ có các triệu chứng GERD điển hình và nhóm có kết hợp triệu chứng GERD điển hình và triệu chứng nghi ngờ trào ngược họng thanh quản. Tuổi trung bình của cả nhóm khoảng 46 tuổi, nữ giới chiếm tỉ lệ là cao hơn nam giới. Không có sự khác biệt về tuổi, giới, BMI giữa các nhóm.

Các bất thường của UESđã được chứng minh có liên quan đến cơ chế bệnh sinh của LPR. ${ }^{1,2,5}$
Trong nghiên cứu của chúng tôi, giá trị trung vị của áp lực UES khi nghỉ ở nhóm LPR là $38,3 \mathrm{mmHg}$. Kết quả này thấp hơn trong nghiên cứu của tác giả Benjamin (2017) trên các bệnh nhân được chẩn đoán GERD và LPR dựa vào điểm lâm sàng và/hoặc trên nội soi tai-mũii-họng $(56,0 \mathrm{mmHg} \quad[35,2-84.3])$ và tác giả Vardar (2012) trên nhóm bệnh nhân có ho và trào ngược mạn tính $(40 \mathrm{mmHg},[1,4-115]){ }^{1,5}$ Sự khác biệt này có thể do loại catheter và hệ thổng đo khác nhau giữa các nghiên cứu. Trong khi nghiên cứu của hai tác giả sử dụng catheter loại đặc với 36 thụ thể cảm nhận áp lực, nghiên cứu 
của chúng tôi sử dụng catheter kênh bơm nước với 22 thụ thể cảm nhận áp lực. Công bố trước đây cho thấy các giá trị trên đo HRM của cơ thắt thực quản dưới (LES) cao hơn khi sử dụng catheter loại đặc so với loại bơm nước, tuy nhiên các giá trị đo của cơ thắt thực quản trên (UES) không có sự khác biệt giữa hai loại catheter. ${ }^{6}$ Bên cạnh đó, trong phân loại Chicago 3.0 cũng chưa có hướng dẫn cụ thể cách phân tích các rối loạn co bóp của UES vào các thời điểm khác nhau (khi nghi, khi nuốt, các nghiệm pháp gắng sức). Nghiên cứu của chúng tôi xác định áp lực UES khi nghỉ là giá trị đo trong 30 giây khi bệnh nhân nằm nghỉ, không có các yếu tố nhiễu như nhịp nuốt, ho. Nghiên cứu của tác giả Benjamin xác định áp lực của UES ở nhịp nuốt nước đơn thứ 10. Do đó, trong tương lai cần nhiều nghiên cứu đánh giá về thông số của UES thay đổi trong quá trình tiến hành kĩ thuật cũng như tư thế thực hiện kĩ thuật để đưa ra hướng dẫn cụ thể và thống nhất trong thực hành lâm sàng.

Áp lực khi nghỉ của UES là một trong các yếu tố duy trì hàng rào chống lại dịch trào ngược từ dạ dày lên họng, thanh quản. ${ }^{2}$ Do đó, đây là một trong các yếu tố thường được sử dụng để đánh giá chức năng của UES trong các tình trạng nghi ngờ trào ngược họng-thanh quản. Trong nghiên cứu, chúng tôi ghi nhận không có sự khác biệt có ý nghĩa thống kê giữa các giá trị đo của UES giữa ba nhóm bệnh nhân khảo sát. Dữ liệu từ các nghiên cứu trên thế giới về kết quả này còn chưa có sự thống nhất. Một nghiên cứu hồi cứu trên 42 bệnh nhân có biểu hiện ho mạn tính theo dõi LPR ghi nhận bệnh nhân có các bất thường họng-thanh quản có áp lực khi nghỉ của UES thấp hơn so với nhóm chứng. ${ }^{7} \mathrm{Nghiên}$ cứu khác của Reza Shaker và cộng sự (2014) cho kết quả khi tăng áp lực vùng UES gián tiếp qua tăng áp vùng sụn thanh quản (cricoid pressure). ${ }^{2}$ Các nghiên cứu trên khẳng định thêm vai trò của trương lực vùng UES trong bệnh lí LPR. Tuy nhiên một số nghiên cứu khác so sánh áp lực UES giữa nhóm ho mạn tính và nhóm chứng bình thường cho thây không có sự khác biệt có ý nghĩa thống kê. ${ }^{8,9}$ Áp lực cặn của UES là một thông số đánh giá áp lực thấp nhất ở vùng UES khi giãn ra trong động tác nuốt. Sự tăng áp lực bất thường của áp lực cặn UES gặp trong các tình trạng "thanh hầu họng" (cricopharyngeal bar) và túi thừa Zenker, và cũng tăng trong các bất thường giãn của UES như ở các bệnh nhân ho mạn tính, cảm giác khối ở cổ. ${ }^{5}$ Một nghiên cứu khác trên các đối tượng có cảm giác có khối ở cổ (globus sensation) cho thây nhóm bệnh nhân có triệu chứng, áp lực cặn của UES (residual pressure) cao hơn có ý nghĩa thống kê so với nhóm chứng bình thường. Điều này gợi ý tăng áp lực cặn của UES làm chậm quá trình thanh thải tại hầu họng (laryngeal clearance) gây ra các biểu hiện lâm sàng trong LPR. ${ }^{5}$

Co bóp không hiêu quả (IEM) là rối loạn nhu động thực quản phổ biến nhấtở cả 3 nhómbệnh nhânvà không có sự khác biệt về tỷ lệ giữa cácnhóm. Kết quả này phù hợp với dữ liệu công bố trước đây trên nhóm bệnh nhân GERD và LPR. ${ }^{1}$ Giảm nhu động thực quản có thể làm giảm khả năng thanh thải của thực quản, tăng thời gian niêm mạc thực quản tiếp xúc với thức ăn và dịch trào ngược từ dạ dày dẩn đến các biểu hiện lẩm sàng và biến chứng của trào ngược. ${ }^{5}$

Nghiên cứu chúng tôi được tiến hành hồi cứu, do đó còn tồn tại một số điểm hạn chế như chưa có nhóm chứng trên đối tượng khỏe mạnh, tiêu chuẩn thu tuyển bệnh nhân các nhóm chỉ dựa trên biểu hiện lâm sàng, chưa kết hợp cùng một số phương pháp đánh giá trào ngược hongthanh quản khác như nội soi tai-mũi-họng và đo $\mathrm{pH}$ trở kháng thực quản 24 giờ. Tuy nhiên, nghiên cứu này đã̃ cung cấp những số liệu ban đầu về một số thông số của UES khi áp dụng HRM trong đánh giá bệnh lí trào ngược họngthanh quản ở người Việt Nam.

\section{KẾT LUẬN}

Trong nghiên cứu của chúng tôi, $1 / 3$ bệnh nhân với triệu chứng nghi ngờ trào ngược họng thanh quản có trương lực UES thấp và gần $2 / 3$ có bất thường giãn UES, tuy nhiên không ghi nhận sự khác biệt có ý nghĩa thống kê so với nhóm có triệu chứng trào ngược điển hình và nhóm có triệu chứng hỗn hợp của trào ngược điển hình và nghi nhờ trào ngược họng thanh quản.

\section{TÀI LIẸU THAM KHẢO}

1. Benjamin T, Zackria S, Lopez R, Richter J, Thota PN. Upper esophageal sphincter abnormalities and high-resolution esophageal manometry findings in patients with laryngopharyngeal reflux. Scand J Gastroenterol. 2017;52(8):816-821.

2. Shaker R, Babaei A, Naini SR. Prevention of esophagopharyngeal reflux by augmenting the upper esophageal sphincter pressure barrier. Laryngoscope. 2014;124(10):2268-2274.

3. Babaei A, Venu M, Naini SR, et al. Impaired upper esophageal sphincter reflexes in patients with supraesophageal reflux disease. Gastroenterology. 2015;149(6):1381-1391.

4. Gerhardt DC, Castell DO, Winship DH, Shuck TJ. Esophageal dysfunction in esophagopharyngeal regurgitation. Gastroenterology. 1980;78(5 Pt 1): 893-897. 
5. Vardar R, Sweis $R$, Anggiansah A, Wong $\mathbf{T}$, Fox MR. Upper esophageal sphincter and esophageal motility in patients with chronic cough and reflux: assessment by high-resolution manometry. Dis Esophagus. 2013;26(3):219-225.

6. Wang $K$, Duan LP, Ge $Y$, Xia ZW, Xu ZJ. A comparative study of 22-channel water-perfusion system and solid-state system with 36-sensors in esophageal manometery. BMC Gastroenterol. 2012;12:157.
7. Passaretti S, Mazzoleni G, Vailati C, Testoni PA. Oropharyngeal acid reflux and motility abnormalities of the proximal esophagus. World J Gastroenterol. 2016;22(40):8991-8998.

8. Perry KA, Enestvedt CK, Lorenzo CS, et al. The integrity of esophagogastric junction anatomy in patients with isolated laryngopharyngeal reflux symptoms. J Gastrointest Surg. 2008;12(11):1880-1887.

9. Tomonaga T, Awad ZT, Filipi CJ, et al. Symptom predictability of reflux-induced respiratory disease. Dig Dis Sci. 2002;47(1):9-14.

\section{ĐIỀU TRI BÊNH NHÂN NGộ ĐộC MộT SỐ MA TÚY TẠI TRUNG TÂM CHỐNG ĐộC BỆNH VIÊ̂N BACCH MAI}

\section{TÓM TẮT}

Mục tiêu: Nhận xét các biên pháp điều trị bênh nhân ngộ độc cấp một số ma túy không phải nhóm opi tại Trung tâm Chống độc Bênh viên Bach Mai. Đối tươning và phương pháp: Nghiên cứu mồ tả 72 bệnh nhẩn ngô đôc cấp ma túy không phải nhóm opi điêuu trị tại Trung tâm Chống độc Bệnh viện Bạch Mai từ tháng 1/2017 đến 6/2019. Kết quả: Các loai ma túy gặp trong nghiên cứu là Amphetamin $(29,2 \%)$, MET $(22,2 \%)$, MDMA $(19,4 \%)$, THC $(20,8 \%)$, Ketamin $(8,3 \%)$. Các biện pháp điêuu trị chính là hối sức tích cực và điều trị hỗ trợ: hồi sức tuần hoàn, sử dung vân mạch $(1,4 \%)$, tăng cường bài niệu $(98,6 \%)$; hỗ trợ hô hẩp $25 \%$ (thở oxy $19,4 \%$, thở máy $5,6 \%$, nhiều nhất là nhóm ketamin); sử dụng an thần 43,1\% (nhiêu nhất ở nhóm amphetamin $61,9 \%$; dùng thuốc diazepam là 90,3\%). Kết quả điêuu trị: khỏi 91,7\%, còn rối loan tâm thân sau điều trị $8,3 \%$. Kết luân: Hiên tai chưa có thuốc kháng độc đắc hiệu nên điêu trị ngộ độc các loại ma túy không phải nhóm opi cần sự phối hợp của các biện pháp hôi sức tích cực, điều trị các triêu chứng và biến chứng.

Tư khóa: ngộ độc ma túy, điều trị.

\section{SUMMARY}

TREATMENT MEASURES FOR DRUGS OF ABUSE POISONING AT POISON CONTROL CENTER OF BACH MAI HOSPITAL

Objective: to evaluate treatment measures for patients with non-opium drugs of abuse poisoning at Poison Control Center, Bach Mai Hospital. Subjects and Methods: A observational study included 72 poisoned non-opium drugs poisoning patients treated at Poison Control Center Bach Mai Hospital from $1 / 2017$ to 6/2019. Results: The drugs found in the study were Amphetamine (29.2\%), MET (22.2\%),

${ }^{1}$ Trung Tâm Chông Độc Bệnh viện Bạch Mai

${ }^{2}$ Bênh viên Lão khoa Trung ương

Chịu trách nhiệm chính: Đặng Thị Xuân

Email: xuandangthi@bachmai.edu.vn

Ngày nhận bài: 25.2.2021

Ngày phản biên khoa hoc: 5.4.2021

Ngày duyệt bài: 13.4 .2021
Đặng Thị Xuân ${ }^{1}$, Nguyễn Trung Anh² MDMA (19.4\%), THC (20.8\%), Ketamine (8.3\%). The applied treatment measures for patients were resuscitation and supportive therapy: cardiovascular support, using vasopressors $(1,4 \%)$, increased diuresis (98.6\%); Respiratory support 25\% (oxygen $19.4 \%$; mechanical ventilation $5.6 \%$, the most in the ketamine group); Using sedation $43.1 \%$ (the most in the amphetamine group 61.9\%; using diazepam was $90.3 \%)$. The outcome: recovery $(91.7 \%)$, mental disorder $8.3 \%$. Conclusion: There was no specific antidote, so the treatment required for poisoning of non-opium drugs was a combination of aggressive resuscitation measures and symptomatic treatment.

Key words: drugs of abuse poisoning, treatment

\section{I. ĐĂT VẤN ĐỀ}

Ma túy là một vấn nạn của nhiều nước trên thế giới cũng như của nước ta. Tại Việt Nam, heroin là ma túy nhóm opi được sử dung nhiều nhất trong những năm trước đây, chiểm $3 / 4$ số loại chất gây nghiên thường được sử dụng, còn lại là cần sa, ma túy tổng hợp [1]. Thời gian gần đây, việc sử dụng các loại ma túy tổng hợp amphetamin và các dẫn chẩt (kẹo, thuốc lắc, ma túy đá...), ketamin, cần sa, lá khát, nấm, bóng cười... ngày càng gia tăng, đặc biệt trong nhóm người trẻ tuổi.

Các loại ma túy không phải opi rất đa dạng, độc tính phức tạp. Ma túy tổng hợp được tổng hợp từ một hoặc nhiều loại tiền chất, hoặc pha trộn với tî̉ lê khác nhau cho ra các loại ma túy khác nhau. Cỏ Mỹ có thể được pha tẩm thêm ma túy tổng hợp... Các ma túy mới xuất hiện nhiều hơn, tình trạng lạm dụng tăng lên, gây khó khăn trong kiểm soát, chẩn đoán và điêu trị. Các loại ma túy mới có độc tính mạnh, phức tạp, không chỉ gây hại cho bản thân bệnh nhân mà còn gây nguy hiểm cho người xung quanh do loạn thân, ảo giác, có trường hợp nhập viện do tổn thương tim, suy tim, loan nhịp tim, hôn mê, suy đa tạng, một số trường hợp tử vong. 